\title{
CLINICAL CHARACTERISTICS OF STROKE IN YOUNG PEOPLE
}

\author{
$\underline{\text { R.Aliyev }}^{1}$, R.Shiraliyeva ${ }^{1}$, N.Mammadova ${ }^{2}$, R.Hasanov ${ }^{1}$ \\ ${ }^{1}$ Azerbaijan State Advanced Training Institute for Doctors named after A.Aliyev, \\ Department of Neurology and clinical neurophysiology, Baku, Azerbaijan; \\ ${ }^{2}$ Republican Clinical Hospital named after acad. M.Mirgasimov, Department of \\ Neurology, Baku, Azerbaijan
}

Background and Aims. In the past decade, strokes at young age is more common. The aim of our research was to study the clinical features of stroke in young people.

Method. The study was conducted in neurology departments of the Republican Clinical Hospital named after M.Mirgasimov (Baku, Azerbaijan). Within 3 years (2014-2016), 145 patients aged from 18 to 45 were examined [men 74 (51\%), women $71(49 \%)]$. Patients were performed by a complete neurological, somatic, laboratory, ultrasonography, neuroimaging examination.

Results. The average age of patients was 35 , for men - 36, for women - 34 years. $39(27 \%)$ of patients, were in the younger age group (18-30 years), and $106(73 \%)$ in older age group (31-45 years). In $116(81 \%)$ patients, stroke was noted as a primary, in 29 (19\%) recurrent. $82(56 \%)$ patients had ischemic stroke (IS), 41 (28\%) an intraparenchymal hemorrhage, 13 (9\%) subarachnoid hemorrhage (SAH) and 9 (7\%) venous sinus thrombosis (VST). It was found that in the older age group, IS and SAH occurs more often (Table 1).

Table 1. Percentage of stroke types in young people

\begin{tabular}{|l|l|l|l|l|}
\hline Age groups & Ischemic stroke & $\begin{array}{l}\text { Intraparenchymal } \\
\text { Hemorrhage } \\
(\mathrm{N}=41)\end{array}$ & $\begin{array}{l}\text { Venous sinus } \\
\text { thrombosis } \\
(\mathrm{N}=9)\end{array}$ & $\begin{array}{l}\text { Subarachnoid } \\
\text { hemorrhage } \\
(\mathrm{N}=13)\end{array}$ \\
\hline $18-30$ years & $19(23 \%)$ & $13(32 \%)$ & $7(78 \%)$ & $0(0 \%)$ \\
\hline $31-45$ years & $63(77 \%)$ & $28(68 \%)$ & $2(22 \%)$ & $13(100 \%)$ \\
\hline
\end{tabular}

In $6(21 \%)$ patients from 29 , who had recurrent stroke, the cerebrovascular accident repeated at the age of 18-30 and in 23 (79\%) in 31-45. The distribution of stroke by sex showed that young women predominate among patients with VST (Table 2).

Table 2. Percentage of stroke types in young people be sex

\begin{tabular}{|l|l|l|l|l|}
\hline Sex & Ischemic stroke & $\begin{array}{l}\text { Intraparenchymal } \\
\text { hemorrhage } \\
(\mathrm{N}=41)\end{array}$ & $\begin{array}{l}\text { Venous sinus } \\
\text { thrombosis } \\
(\mathrm{N}=9)\end{array}$ & $\begin{array}{l}\text { Subarachnoid } \\
\text { hemorrhage } \\
(\mathrm{N}=13)\end{array}$ \\
\hline Women & $41(50 \%)$ & $19(46 \%)$ & $9(100 \%)$ & $5(38 \%)$ \\
\hline Men & $41(50 \%)$ & $22(54 \%)$ & $0(0 \%)$ & $8(62 \%)$ \\
\hline
\end{tabular}

Conclusion. At young age, IS prevails. In the older age group, ischemic stroke and SAH are more common. VST is more common in women.

Keywords: young people, stroke, women, subarachnoid hemorrhage, venous sinus thrombosis. 